Research Article

\title{
Study on the Dynamic Response Characteristics of Cylindrical Coal-Rock Samples under Dynamic Loads
}

\author{
Hongqing Zhu $\mathbb{D}^{1,},{ }^{1,2}$ Shuhao Fang $\mathbb{D}^{1,2}$ Yilong Zhang $\mathbb{D}^{1},{ }^{1}$ and Yan $W u^{1}$ \\ ${ }^{1}$ School of Emergency Management and Safety Engineering, China University of Mining and Technology-Beijing, \\ Beijing 100083, China \\ ${ }^{2}$ State Key Laboratory of Coal Resources and Safe Mining, China University of Mining and Technology-Beijing, \\ Beijing 100083, China \\ Correspondence should be addressed to Shuhao Fang; 13051880533@163.com
}

Received 17 August 2020; Revised 1 December 2020; Accepted 4 December 2020; Published 16 December 2020

Academic Editor: Xihui Liang

Copyright ( $\odot 2020$ Hongqing Zhu et al. This is an open access article distributed under the Creative Commons Attribution License, which permits unrestricted use, distribution, and reproduction in any medium, provided the original work is properly cited.

\begin{abstract}
To research the dynamic response characteristics of cylindrical coal-rock samples under impact loads, the impact of rigid bars on cylindrical coal-rock samples is simulated under different speed conditions, based on LS-DYNA software, and the dynamic distribution characteristics of the stress, strain, and energy of cylindrical coal-rock samples are analyzed. The results demonstrated the following: (1) the cylindrical coal-rock sample failed at the center first, and the damage developed downward along the axial direction. (2) The critical effective stress and strain have an exponential function relationship with the velocity, and the critical time has a linear relationship with the velocity. (3) The energy change law of the cylindrical coal-rock sample is consistent with the destruction morphology. (4) The axial stress peaks in the severe damage part have a linear relationship with the speed, the axial stress attenuates rapidly after passing the stress yield point, and the axial strain does not increase continuously. (5) The peaks stress and strain on the central axis and the radial line obey the power function distribution, the axial stress produces tensile stress in the axial propagation direction, and the axial stress and strain peaks at the same position are larger than those of the radial stress and strain peaks. This research provides a reference for studying coal and rock dynamic disasters.
\end{abstract}

\section{Introduction}

The effect of the impact load on coal-rock sample mechanics is the basis of mining [1]. Dynamic disasters such as coal and gas outbursts and rock bursts occur suddenly, develop rapidly, are destructive, and sweep over a wide range. They are likely to cause secondary accidents and pose a threat to the safety of a mine [2-4]. After a mine enters the deep mining stage, the geological conditions of the coal mine become more complicated $[5,6]$. To solve these problems, it is necessary to understand the law and mechanism of the deformation, failure, and fracture evolution of coal-rock masses [7]. Mining activities and coal-rock kinetics responses are the main sources of mining dynamic loads [8].

Coal and rock masses are mainly compressed and sheared under static loading [9-14]. The split-Hopkinson pressure bar (SHPB) is the main experimental device that is used to explore the mechanism of coal mass dynamic damage [15-17]. Feng et al. [18] conducted dynamic loading tests on coal using an SHPB system, and the mechanism of energy dissipation was discussed based on the fracture processes of coal under dynamic loads. Yin et al. [19] performed dynamic compression experiments on coal-rock using SHPBs and found that the peak strain decreased when the peak stress increased. Based on the SHPB experiment and RMT-150C test systems, Wang et al. [20] reported that the dynamic strength of $7 \mathrm{D}$ saturated coal specimens is lower than that of natural coal specimens under one-dimensional static-dynamic loading. Gong et al. [21] used the SHPB experiment to conclude that the dynamic compressive strength (the second peak stress) and dynamic peak strain (the second peak strain) of the coal-rock combined body have a strong loading rate effect and will generally increase linearly with the loading rate. Wang et al. [22] established a 
fracture model of a hydrous wing branch fracture under static-dynamic loading based on the SHPB and RMT-150 system tests. Yang et al. [23] used the SHPB to study the strength and microstructures of outburst-prone coal under compressive impact loading. Yin et al. [24] studied the dynamic behaviors of the strain and energy changes of gascontaining coal under the SHPB test, with the condition of controlling the initial gas pressure and the axial static preload. Kong et al. [25] analyzed the relationship among the dynamic strength, failure strain and axial static load, confining pressure, air pressure, and impact load, based on a split-Hopkinson pressure bar experimental system. Ai et al. [26] used SHPB experiments to study the crack propagation and dynamic mechanical properties of coal under high strain rate loading. Liao et al. [27] studied the tensile and compressive properties of rock based on SHPB experiments. Li et al. [28] demonstrated the strain, stress, displacement, vibration velocity, and energy distribution in all directions of cylindrical coal-rock samples in high-order P-waves. It can be seen from the above literature that SHPB experimental research has difficulty monitoring the dynamic change process of various parameters at the internal points of the sample.

Numerical simulation research has certain advantages compared with experimental research [29]. Hao et al. and Li et al. [30,31] studied the tensile and compressive properties of concrete materials based on the numerical simulation of the SHPB experiment. Li et al. and Zhu et al. [32-34] studied the mechanical properties of rock materials based on numerical simulations of SHPB experiments. Zhao et al. [35] applied LS-DYNA software to the constitutive model considering the dynamic compression and tensile failure for the analysis of crack propagation caused by coal blasting. Majidi et al. [36] and Zhai et al. [37] used LS-DYNA software to study the properties of concrete. Yuan et al. [38] simulated the rock SHPB experiment of the Holmquist-Johnson-Cook (HJC) model based on LS-DYNA software. Xie et al. [39] analyzed the numerical simulation with the failure form of coal-rock under dynamic loading based on the HJC model.

According to past studies in the available literature, the damage characteristics of coal-rock samples under dynamic loading have been insufficiently studied. Research on the damage mechanism of coal-rock samples under dynamic loading has mostly focused on the overall shape after failure and the overall stress, strain, energy dissipation, and compressive strength during the failure process. There are few studies on the damage characteristics of the internal points of coal-rock samples. This paper took cylindrical coal-rock samples as the research object. The cylindrical coal-rock sample impact experiment based on the HJC model was simulated by LS-DYNA software, and the failure characteristics and internal dynamic response characteristics of the cylindrical coal-rock samples during the failure process were analyzed. This research is helpful for deeply understanding the dynamic response characteristics of coal-rock samples under impact dynamic loads and provides a reference for studying coal and rock dynamic disasters.

\section{HJC Constitutive Model and Modeling of Coal-Rock Sample}

The units of quality, time, and length used in the LS_DYNA program are $g, \mu \mathrm{s}$, and $\mathrm{cm}$, respectively. Table 1 provides the rigid body model parameters of the impact bar.

The HJC dynamic constitutive model can be established in the LS-DYNA package [40]. The HJC model is capable of simulating the large deformation problems of concrete under high pressure and a high strain rate [41]. The equivalent yield strength is a function of the pressure, strain rate, and damage. The pressure is a function of the volumetric strain and contains the effects of permanent crushing. Damage accumulation is a function of the plastic volumetric strain, equivalent plastic strain, and pressure. The damage accumulation mainly contains the strength equation, damage evolution equation, and state equation [42]. The LSDYNA package generates cracks in the structure through the failure of the unit. Table 2 provides the HJC model parameters of the coal-rock sample with reference to the HJC model definition and related literature [39, 43, 44].

The model was established with a cylindrical coal-rock sample with a diameter of $50 \mathrm{~mm}$ and height of $100 \mathrm{~mm}$, an impact bar with a diameter of $60 \mathrm{~mm}$ and height of $200 \mathrm{~mm}$, and a gasket with a diameter of $64 \mathrm{~mm}$ and height of $20 \mathrm{~mm}$. To reduce the amount of simulation operation, actual onequarter symmetric size modeling was adopted. The vertical displacement constraint and the nonreflection boundary condition were set on the model symmetry plane. The cylindrical coal-rock samples adopted the HJC material model, and the impact bar and the gasket were established by the rigid body material model. The model was meshed by the hexagonal mapping method and adopted the three-dimensional solid element. The radial line, central axis, and edge axis of the cylindrical coal-rock samples on the model are shown in Figure 1.

In the simulation, the gasket was fixed, the cylindrical coal-rock sample was located on the gasket, which had a displacement constraint in the direction of the vertical gasket, and the impact bar impacted the cylindrical coal-rock sample at a certain speed. After several simulation tests, based on the SHPB experiment, representative speeds were selected for analysis. The simulated speeds of the impact bar were $0.125 \mathrm{~m} / \mathrm{s}, 0.25 \mathrm{~m} / \mathrm{s}, 0.5 \mathrm{~m} / \mathrm{s}, 1 \mathrm{~m} / \mathrm{s}, 2 \mathrm{~m} / \mathrm{s}, 4 \mathrm{~m} / \mathrm{s}, 6 \mathrm{~m} / \mathrm{s}$, $8 \mathrm{~m} / \mathrm{s}$, and $10 \mathrm{~m} / \mathrm{s}$. The dynamic response characteristics of the cylindrical coal-rock samples were calculated under nine speeds.

\section{Damage of the Cylindrical Coal-Rock Samples under Different Impact Speeds}

3.1. Effective Stress, Effective Strain, and Morphological Changes. The final effective stress distributions on the longitudinal section at speeds of $0.125 \mathrm{~m} / \mathrm{s}, 0.25 \mathrm{~m} / \mathrm{s}, 0.5 \mathrm{~m} / \mathrm{s}$, $1 \mathrm{~m} / \mathrm{s}, 2 \mathrm{~m} / \mathrm{s}, 4 \mathrm{~m} / \mathrm{s}, 6 \mathrm{~m} / \mathrm{s}, 8 \mathrm{~m} / \mathrm{s}$, and $10 \mathrm{~m} / \mathrm{s}$ are shown in Figures 2(a)-2(i). The stress and morphological changes of the cylindrical coal-rock samples are similar under different speed conditions (the coal-rock sample does not break at a 
TABLE 1: Rigid body model parameters.

\begin{tabular}{lcc}
\hline Density $\left(\mathrm{kg} \mathrm{m}^{-3}\right)$ & Elastic modulus $(\mathrm{GPa})$ & Poisson's ratio \\
\hline 7900 & 210 & 0.3 \\
\hline
\end{tabular}

TABLE 2: HJC model parameters of the coal-rock.

\begin{tabular}{lcccccccc}
\hline$\rho_{0}\left(\mathrm{~kg} \mathrm{~m}^{-3}\right)$ & $G(\mathrm{GPa})$ & $K_{1}(\mathrm{GPa})$ & $D_{1}$ & $K_{3}(\mathrm{GPa})$ & $\sigma_{\max }(\mathrm{MPa})$ & $B$ & $C$ & $T(\mathrm{MPa})$ \\
\hline 1500 & 0.58 & 85 & 0.0027 & 208 & 10 & 0.7 & 0.05 & 1.86 \\
\hline$f_{c}^{*}(\mathrm{MPa})$ & $N$ & $K_{2}(\mathrm{GPa})$ & $D_{2}$ & $P_{\mathrm{c}}(\mathrm{MPa})$ & $S_{\max }(\mathrm{MPa})$ & $A$ & $u_{c}$ & $P_{\min }(\mathrm{MPa})$ \\
\hline 9 & 0.5 & -171 & 1 & 3 & 7 & 0.4 & 0.0008 & -0.3 \\
\hline
\end{tabular}

Note. $\rho_{0}, \mathrm{fc}{ }^{*}, \mathrm{G}, \mathrm{N}, \mathrm{K} 1, \mathrm{~K} 2$, and K3, D1 and D2, Pc, $\sigma_{\max }$, Smax, A, B, C, uc, T, and Pmin are defined as the density, quasi-static uniaxial compressive strength of coal, shear modulus, pressure hardening exponent, constants used for the material with no voids, damage constants, pressure, failure principal stress, normalized maximum strength, normalized cohesive strength, normalized pressure hardening coefficient, strain rate coefficient, volumetric strain, tensile strength, and minimum failure pressure, respectively.

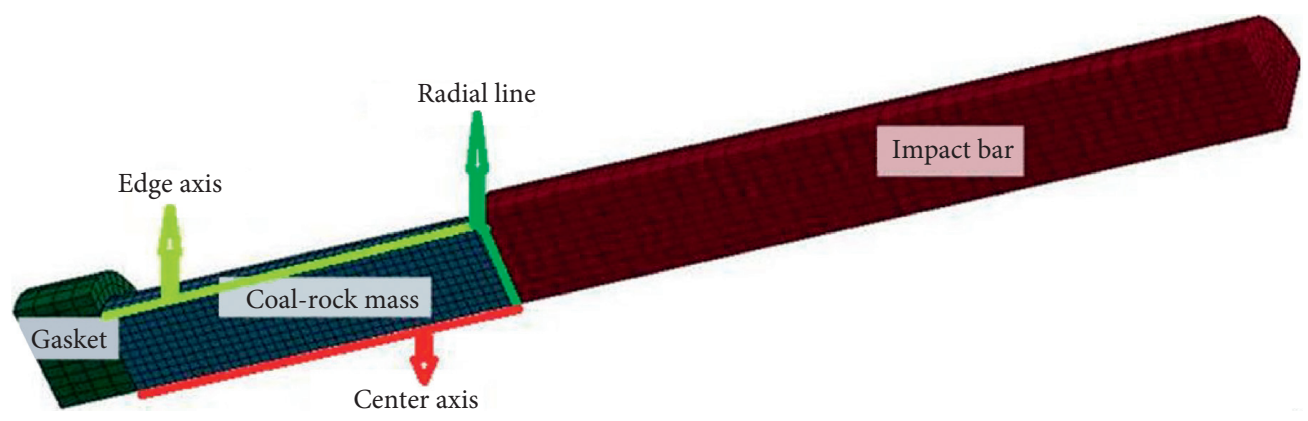

Figure 1: Schematic diagram of the HJC constitutive model.

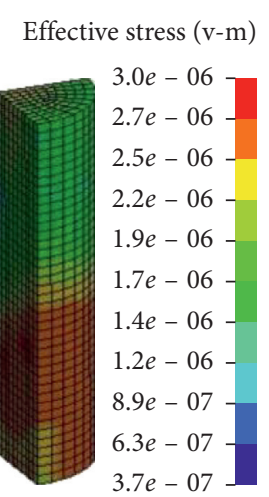

(a)

Effective stress (v-m)

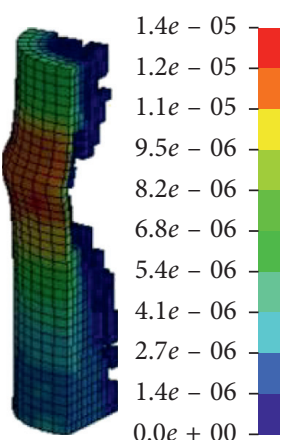

(e)

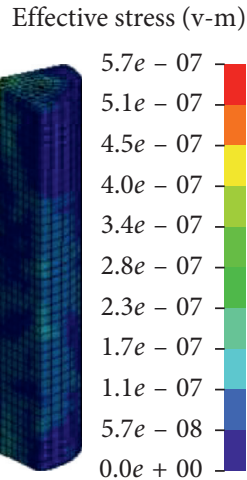

(b)

Effective stress (v-m)

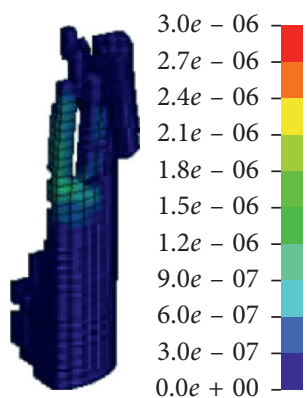

(f)
Effective stress (v-m)

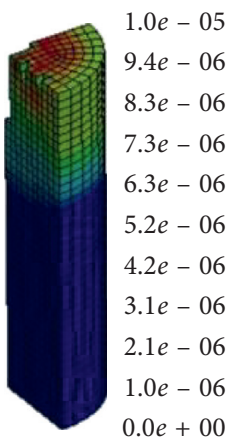

(c)

Effective stress (v-m)

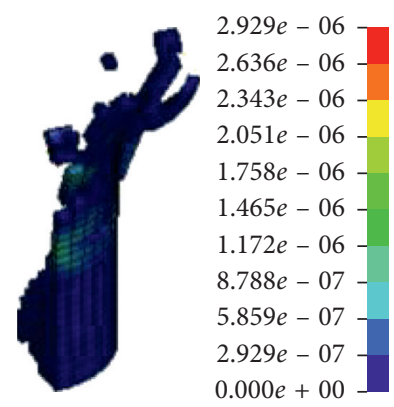

(g)
Effective stress (v-m)

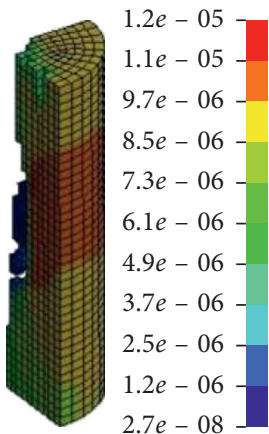

(d)

Effective stress (v-m)

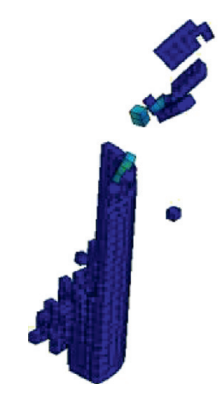

$4.528 e-07$

$4.075 e-07$

$3.622 e-07$

- $3.170 e-07$ -

$2.717 e-07$

$2.264 e-07-$

$1.811 e-07-$

$1.358 e-07$

$9.056 e-08$

$4.528 e-08$

$0.000 e+00$

Figure 2: Continued. 


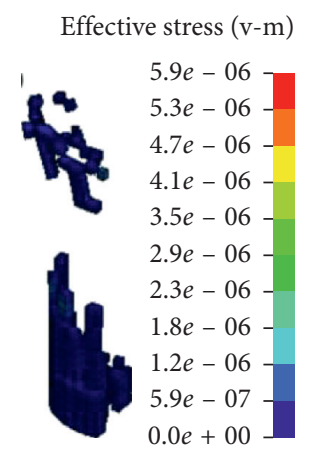

(i)

Figure 2: Distribution of the effective stress on the longitudinal section. (a) $0.125 \mathrm{~m} / \mathrm{s}$. (b) $0.25 \mathrm{~m} / \mathrm{s}$. (d) $1 \mathrm{~m} / \mathrm{s}$. (e) $2 \mathrm{~m} / \mathrm{s}$. (f) $4 \mathrm{~m} / \mathrm{s}$. (g) $6 \mathrm{~m} / \mathrm{s}$. (h) $8 \mathrm{~m} / \mathrm{s}$. (i) $10 \mathrm{~m} / \mathrm{s}$.

speed of $0.125 \mathrm{~m} / \mathrm{s}$ ), and the damage degree increases with increasing velocity.

The effective stress distributions when the impact velocity is $6 \mathrm{~m} / \mathrm{s}$ at $2 \mu \mathrm{s}, 6 \mu \mathrm{s}, 7 \mu \mathrm{s}, 18 \mu \mathrm{s}, 72 \mu \mathrm{s}$, and $5000 \mu \mathrm{s}$ are shown in Figures 3(a)-3(f). The maximum effective stress of the cylindrical coal-rock sample is moved from the edge of the contact surface to the center of the contact surface, reaching the maximum stress at this location, which is called the maximum effective stress. Then, the cylindrical coal-rock sample fails in the center and develops axially downward.

The effective stress at the moment of failure of cylindrical coal-rock samples is called the critical effective stress, and the corresponding time and effective strain are called the critical time and the critical effective strain, respectively, under different speeds. Taking the speed as the independent variable and taking the critical effective stress and the critical time as the dependent variables, the fitting curves are shown in Figure 4. The critical effective stress of the cylindrical coal-rock samples increases with increasing speed, but the increasing amount gradually decreases and tends to a fixed value, indicating that the impact speed can change the critical effective stress of cylindrical coal-rock samples.

The critical time decreases linearly with increasing speed, indicating that the greater the velocity is, the faster the transfer is. The relationship between the critical effective stress and the impact velocity has an exponential function, and the critical time has a linear relationship with the impact velocity.

Taking the impact velocity as the independent variable and the critical effective strain as the dependent variable, the fitting curve is shown in Figure 5. The critical effective strain increases with increasing velocity, and the increase gradually decreases and tends to a fixed value, indicating that dynamic loading can change the effective strain of cylindrical coalrock sample damage. The relationships between the critical effective strain and the impact velocity have exhibited an exponential function. The critical effective stress and strain of the cylindrical coal-rock samples have the same trend as the change in velocity, which indicates that the stress and deformation of the cylindrical coal-rock samples are consistent. When the dynamic load is large, the effective stress and effective strain of the cylindrical coal-rock samples are also large, and the damage is also more serious.

3.2. Energy Time History. The internal energy here is the internal energy converted from kinetic energy when the quarter coal-rock samples are subjected to a dynamic load. The total energy is the sum of the kinetic energy and internal energy obtained by the quarter coal-rock samples under the dynamic load. The cylindrical coal-mass sample has not been damaged at a speed of $0.125 \mathrm{~m} / \mathrm{s}$, and the energy-time history is shown in Figure 6. By impact loading, the kinetic energy of the cylindrical coal-rock sample instantaneously reaches the maximum value at the beginning, and the kinetic energy is almost converted into internal energy at the last moment. The total energy of the cylindrical coal-rock sample drops slightly during the impact.

The cylindrical coal-rock sample is slightly damaged at speeds of $0.25 \mathrm{~m} / \mathrm{s}, 0.5 \mathrm{~m} / \mathrm{s}, 1 \mathrm{~m} / \mathrm{s}$, and $2 \mathrm{~m} / \mathrm{s}$, and the energy-time history at a speed of $2 \mathrm{~m} / \mathrm{s}$ is shown in Figure 7. The speed and proportion of the conversion of kinetic energy into internal energy gradually decrease. The total energy decreases slightly with time.

The cylindrical coal-rock sample is seriously damaged at speeds of $4 \mathrm{~m} / \mathrm{s}, 6 \mathrm{~m} / \mathrm{s}, 8 \mathrm{~m} / \mathrm{s}$, and $10 \mathrm{~m} / \mathrm{s}$. The energy-time history at a velocity of $4 \mathrm{~m} / \mathrm{s}$ is shown in Figure 8 . After failure, only a small part of the kinetic energy is converted into internal energy, most of the energy is in the form of kinetic energy, the proportion of the internal energy is small, and the total energy decreases slightly with time.

Taking the impact velocity as the independent variable and the total energy peak and internal energy peak of the cylindrical coal-rock sample and kinetic energy of the impact bar as the dependent variables, the relationships are shown in Figure 9. The total energy peak increases exponentially with increasing speed. The internal energy peak of the cylindrical coal-rock sample first increases and then decreases with increasing velocity and reaches a maximum value when the impact velocity is $2 \mathrm{~m} / \mathrm{s}$. The cylindrical coal-rock sample is severely damaged if the impact velocity is greater than $2 \mathrm{~m} / \mathrm{s}$; by combining the relationship between internal energy and impact speed, we can get that the cylindrical coal-rock sample will be 


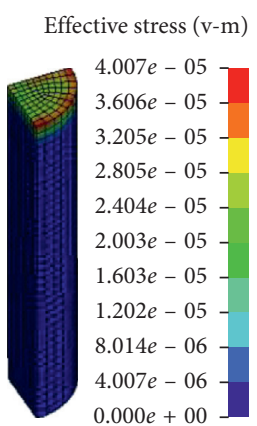

(a)

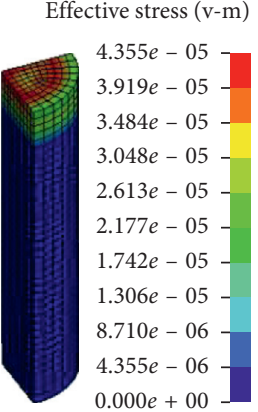

(b)

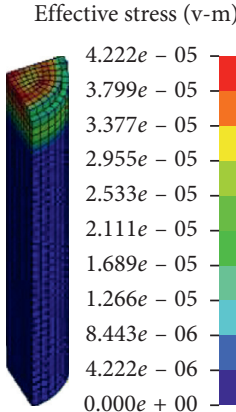

(c)

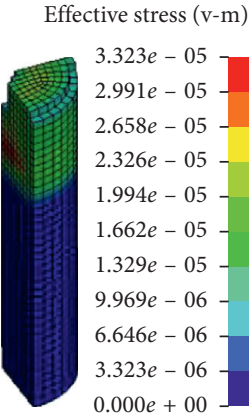

(d)

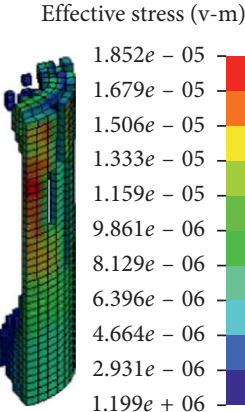

(e)

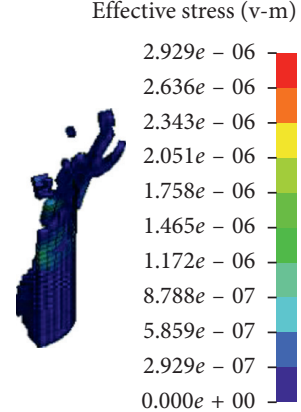

(f)

FIGURE 3: The effective stress distribution at an impact velocity of $6 \mathrm{~m} / \mathrm{s}$. (a) $2 \mu \mathrm{s}$. (b) $6 \mu \mathrm{s}$. (c) $7 \mu \mathrm{s}$. (d) $18 \mu \mathrm{s}$. (e) $72 \mu \mathrm{s}$. (f) $5000 \mu \mathrm{s}$.

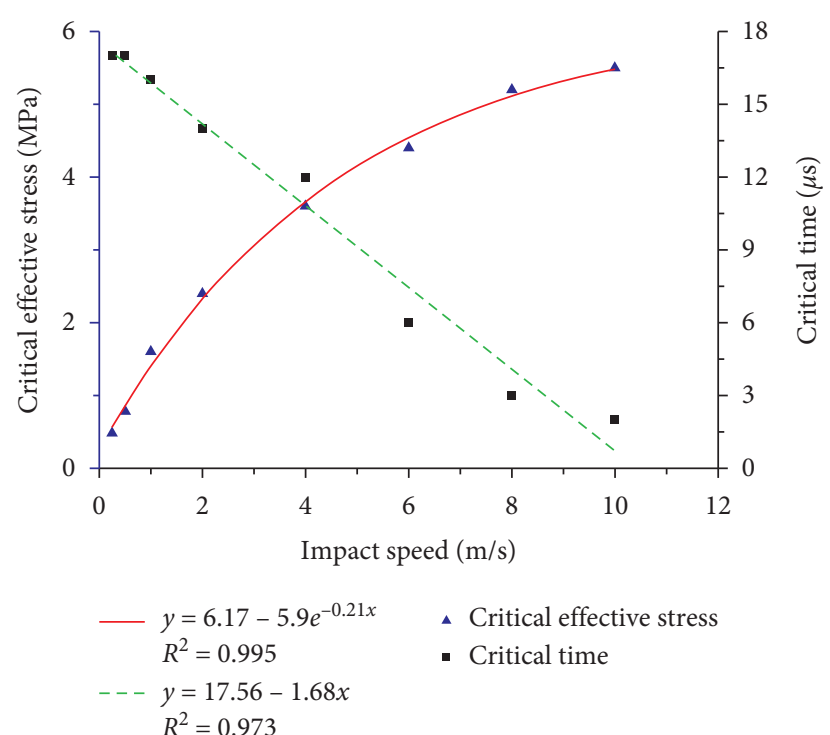

FIGURE 4: Fitting curves of critical effective stress, critical time, and speed.

destroyed after the internal energy peak reaches a certain value under different impact speeds. The energy change law of the cylindrical coal-rock sample is consistent with the destruction morphology of the cylindrical coal-rock sample.

The kinetic energy of the impact bar equation can be expressed as

$$
E_{k}=\frac{1}{2} m v^{2}=\frac{1}{2} \rho \pi r^{2} h v^{2}
$$

where $E_{k}, m, \mathrm{v}, \rho, r$, and $h$ are defined as the kinetic energy, mass, speed, density, radius, and height of the impact bar, respectively.

The parameters of the impact bar and the impact velocity are substituted into equation (1) to obtain the corresponding kinetic energy of the impact bar, as shown in Figure 9. After calculation, the kinetic energy of the impact bars at different impact speeds is approximately equal to the total energy obtained by the cylindrical coal-rock samples, and the fitting equations of the two are consistent.

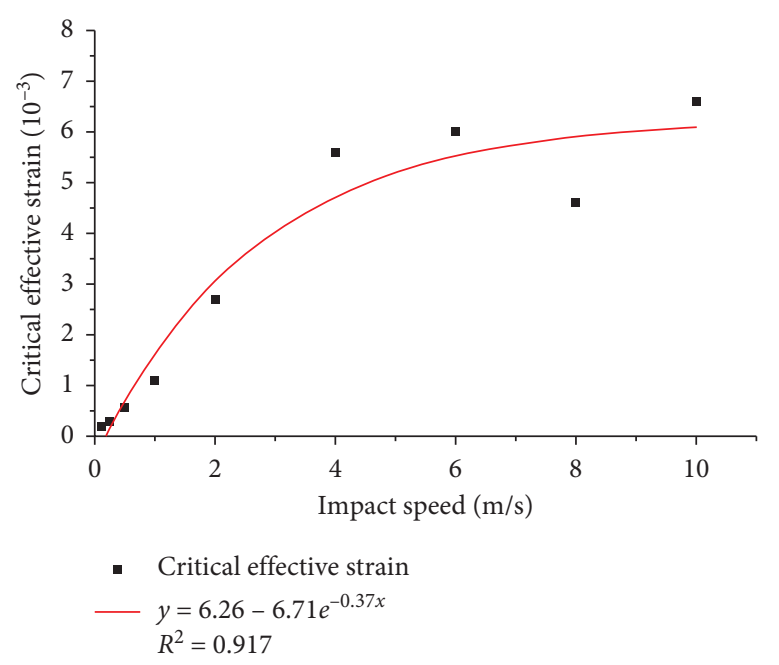

FIgURE 5: Fitting curve of the speed and critical effective strain.

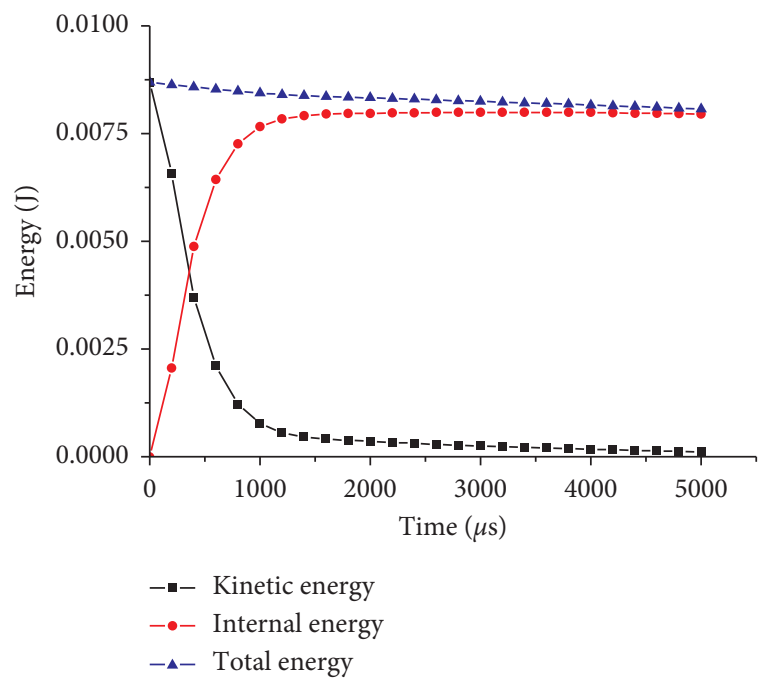

Figure 6: Energy time history at a velocity of $0.125 \mathrm{~m} / \mathrm{s}$.

3.3. Element Point Axial Stress-Strain Curve. Six-element points were selected on the cylindrical coal-rock sample, and the axial stress-strain curve of each element point was analyzed. The six-element points included the apex on the 


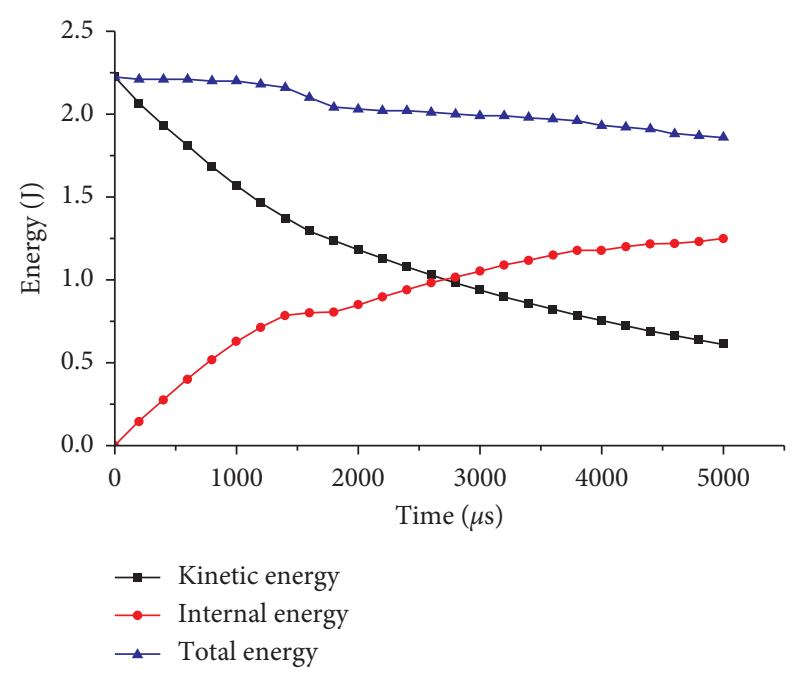

FIgURE 7: Energy time history at a velocity of $2 \mathrm{~m} / \mathrm{s}$.

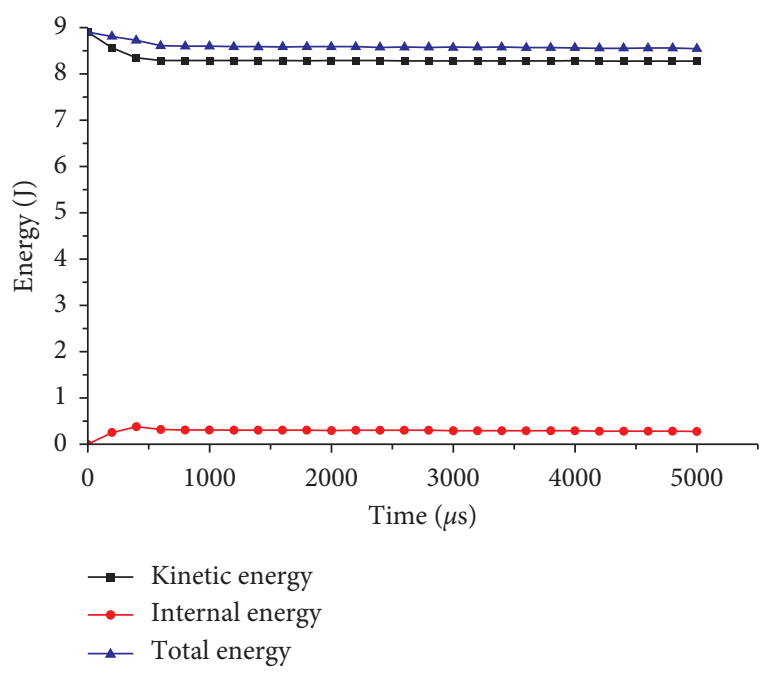

FIGURE 8: Energy-time history at a velocity of $4 \mathrm{~m} / \mathrm{s}$.

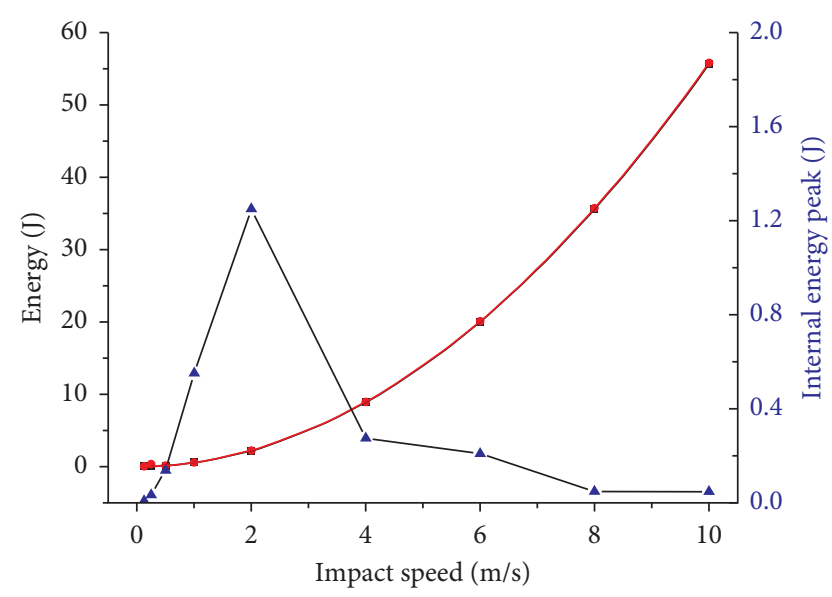
- Total energy peak
- The kinetic energy
$-y=0.55603 x^{2} \quad R^{2}=1$
of the impact bar
$y=0.55814 x^{2} \quad R^{2}=1$
- $\Delta-$ Internal energy peak

Figure 9: Energy and speed. central axis, the midpoint on the central axis, the bottom point on the central axis, the apex on the edge axis, the midpoint on the edge axis, and the bottom point on the edge axis of the cylindrical coal-rock sample. When the impact speed is $0.125 \mathrm{~m} / \mathrm{s}, 0.5 \mathrm{~m} / \mathrm{s}, 4 \mathrm{~m} / \mathrm{s}$, and $10 \mathrm{~m} / \mathrm{s}$, the axial stress-strain curves of the six-element points are shown in Figures 10(a)-10(d).

When the impact speed is $0.125 \mathrm{~m} / \mathrm{s}$, the axial stressstrain curve of the six-element points tends to conform to the static-mechanical stress-strain curve. When the speeds are $0.25 \mathrm{~m} / \mathrm{s}, 0.5 \mathrm{~m} / \mathrm{s}, 1 \mathrm{~m} / \mathrm{s}, 2 \mathrm{~m} / \mathrm{s}$, and $4 \mathrm{~m} / \mathrm{s}$, the axial stressstrain curve of the six-element points does not completely conform to the static-mechanical stress-strain curve change, and the axial stress-strain curve of the apex and the midpoint on the central axis quickly decays after passing the yield point. When the speeds are $6 \mathrm{~m} / \mathrm{s}, 8 \mathrm{~m} / \mathrm{s}$, and $10 \mathrm{~m} / \mathrm{s}$, the axial stress-strain curves of the six-element points quickly decay after passing the yield point. In the part where the cylindrical coal-rock sample is severely damaged by impact loading, the axial stress attenuates rapidly after passing the stress yield point, and the axial strain does not continuously increase, which is different from the constant increase in the strain under static loading.

Taking the impact bar velocity as the independent variable and the peak value of the axial stress of the sixelement points as the dependent variable, the fitting curve is shown in Figure 11.

The axial stress peaks of the apex on the central axis, the midpoint on the central axis, and the apex on the edge axis of the cylindrical coal-rock sample have a linear relationship with the impact speed. The damage of the coal-rock samples in the three parts is also obvious, and the peak values of the axial stress of these three element points are also relatively large.

The literature $[45,46]$ uses an SHPB to obtain the stressstrain curve of coal samples at different strain rates. After the yield point, the stress rapidly decays, the axial strain does not continuously increase, and the peak stress increases linearly with increasing strain rate, which is consistent with the conclusions of the numerical simulation in this paper.

\section{Discussion on the Axial and Radial Stress and Strain Distribution}

When the impact speed is $10 \mathrm{~m} / \mathrm{s}$, the cylindrical coal-rock sample is the most severely damaged, which is a dynamic load damage and the axial stress distributions at $3 \mu \mathrm{s}, 13 \mu \mathrm{s}$, $18 \mu \mathrm{s}, 29 \mu \mathrm{s}$, and $1000 \mu \mathrm{s}$ are shown in Figures 12(a)-12(e). The maximum axial stress is located in the center of the contact surface and develops along the central axis. The point of the maximum value of axial stress is the first point to be destroyed, and the failure point and the maximum axial stress are consistent.

On the central axis of the cylindrical coal-rock sample, fourteen element points are equidistantly selected from the top to the bottom. When the impact speed is $10 \mathrm{~m} / \mathrm{s}$, the axial stress time history of the fourteen element points is shown in Figure 13. The axial stress on the central axis develops from top to bottom, and the axial stress peak decreases 

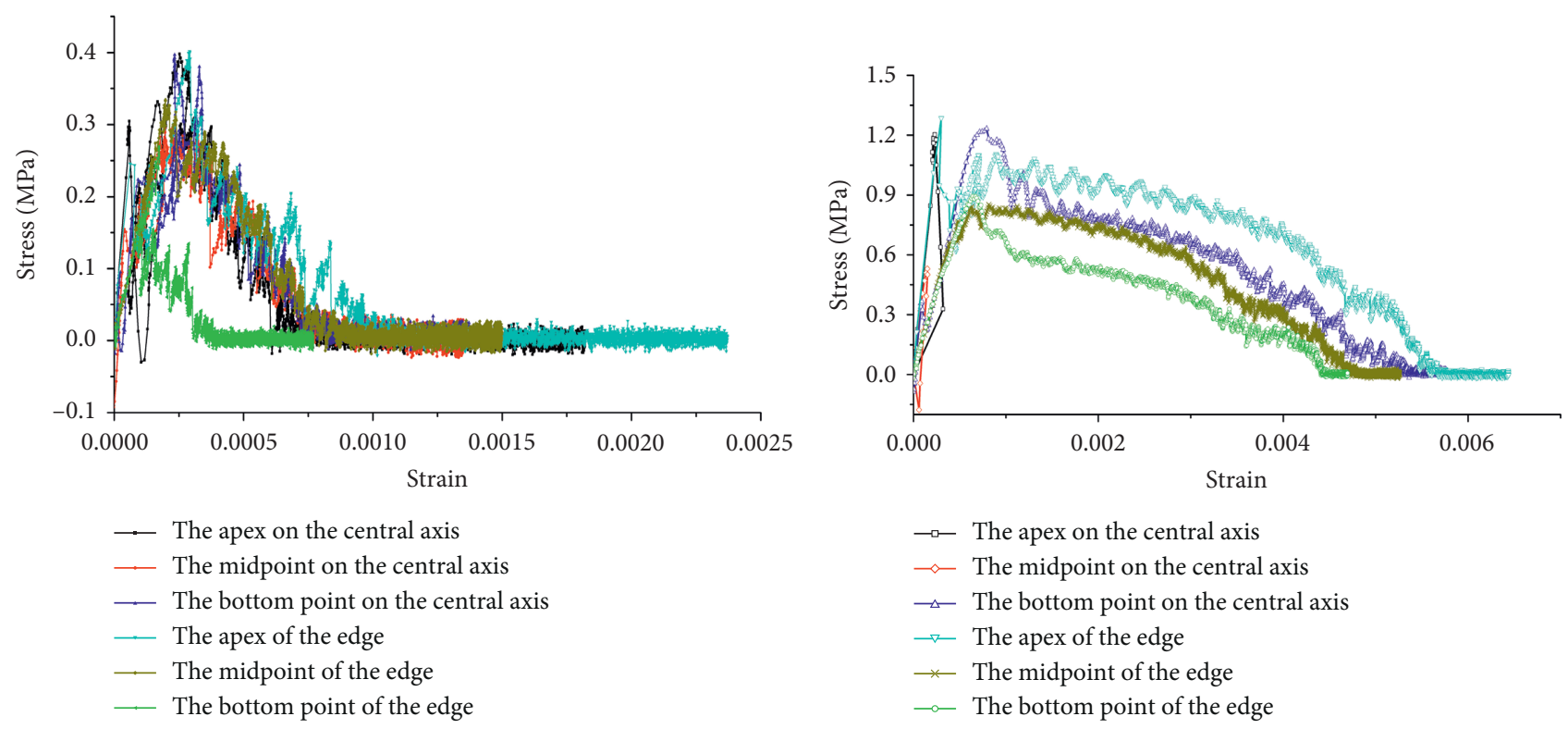

(a)

(b)

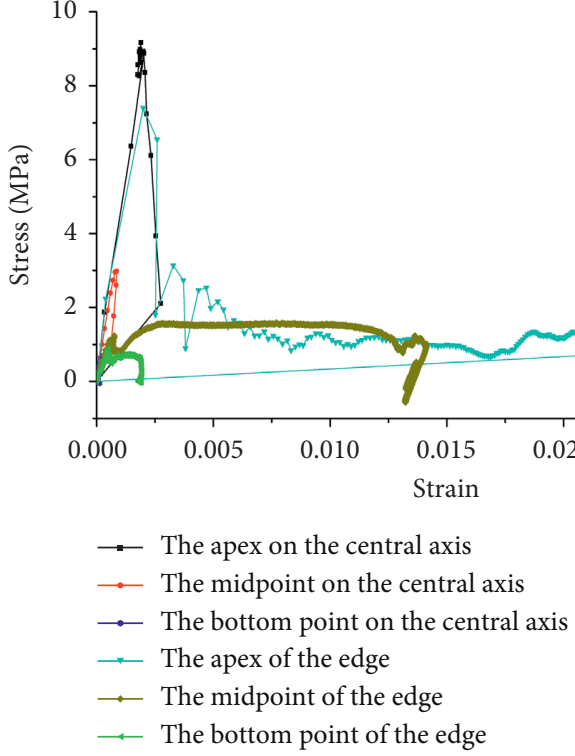

(c)

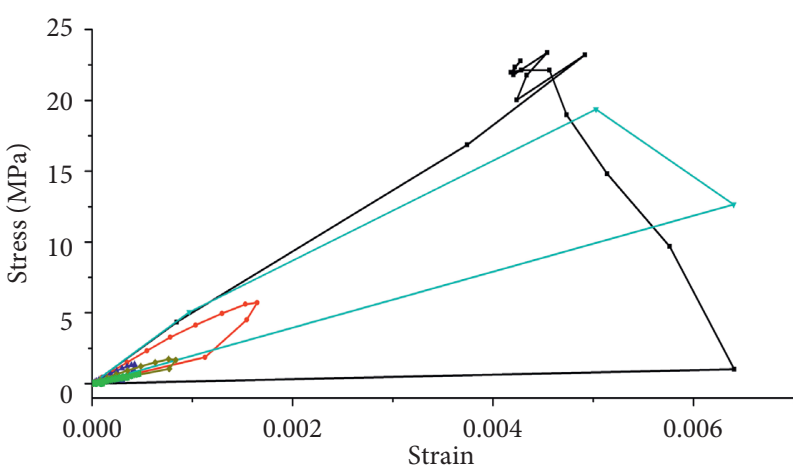

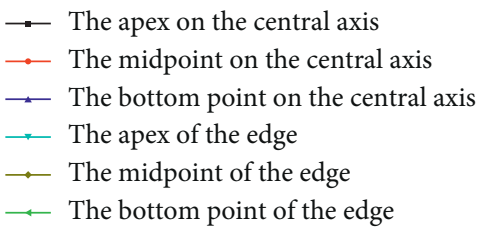

(d)

FIGURE 10: Element point axial stress-strain curve. Stress and strain at a speed of (a) $0.125 \mathrm{~m} / \mathrm{s}$, (b) $0.5 \mathrm{~m} / \mathrm{s}$, (c) $4 \mathrm{~m} / \mathrm{s}$, and (d) $10 \mathrm{~m} / \mathrm{s}$.

continuously. The axial stress is the compressive stress in the axial direction. When the axial stress at the apex of the coalrock sample exceeds the peak value, the axial stress behind the direction of propagation of the axial stress is smaller than that of the front. At the same moment, the cylindrical coal-rock sample is prone to damage in the axial stress propagation cross section where the axial stress becomes tensile stress.

The distribution of the axial stress peak, radial stress peak, axial strain peak, and radial strain peak at fourteen element points on the central axis of the cylindrical coal-rock sample are shown in Figures 14 and 15, respectively. The axial stress peak, radial stress peak, axial strain peak, and radial strain peak distribution of the central axis are in accordance with the Farazdagiharris-type power function, and the correlation coefficient square $\left(R^{2}\right)$ is greater than 0.98 . The axial stress peak at the same position is greater than the radial stress peak, and the axial strain peak is greater than the radial strain peak.

The axial stress and radial stress distribution on the cross section of the cylindrical coal-rock sample at a velocity of $10 \mathrm{~m} / \mathrm{s}$ are shown in Figures 16(a) and 16(b). The maximum stress is at the center of the circle.

Ten element points are equidistantly selected from the center to the edge on the radial line of the contact surface of the cylindrical coal-rock sample. The axial stress time history of the ten element points at impact speed $10 \mathrm{~m} / \mathrm{s}$ is shown in Figure 17. The axial stress on the radial line 


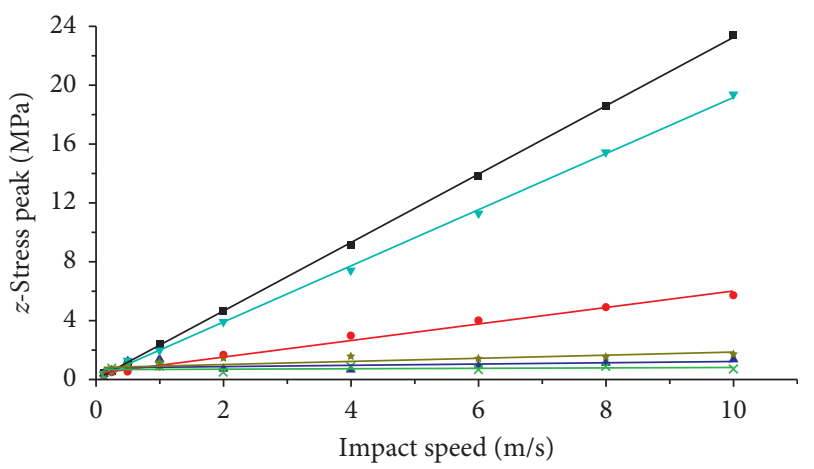

- The apex on the central axis

- The midpoint on the central axis

- The bottom point on the central axis

- The apex of the edge

* The midpoint of the edge

$\times$ The bottom point of the edge

Fitting curve

$\begin{aligned} y=0.019+2.321 x & R^{2}=1.000 \\ y=0.399+0.562 x & R^{2}=0.989 \\ y=0.789+0.042 x & R^{2}=0.073 \\ -y=0.097+1.907 x & R^{2}=0.999 \\ y=0.812+0.105 x & R^{2}=0.574 \\ -y=0.676+0.013 x & R^{2}=-0.087\end{aligned}$

Figure 11: Fitting curve of the impact speed and axial stress peak.

$Z$-stress

$1.495 e-06$

$-2.892 e-05$

$-5.933 e-05$

$-8.974 e-05$

$-1.202 e-04$

$-1.506 e-04$

$-1.810 e-04$

$-2.114 e-04$

$-2.418 e-04$

$-2.722 e-04$

$-3.026 e-04$

(a)
Z-stress

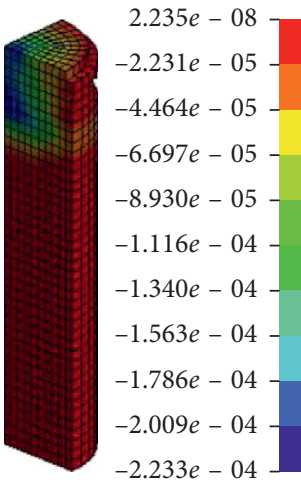

(b)
Z-stress

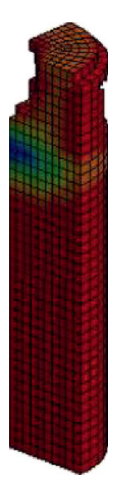

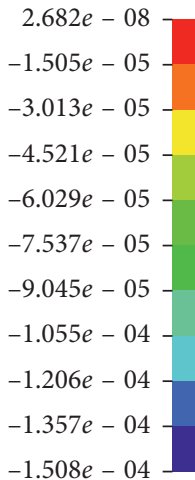

(c)
$Z$-stress

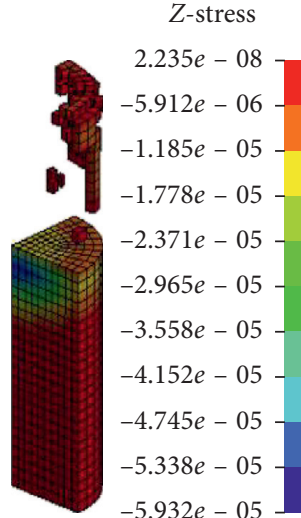

(d)

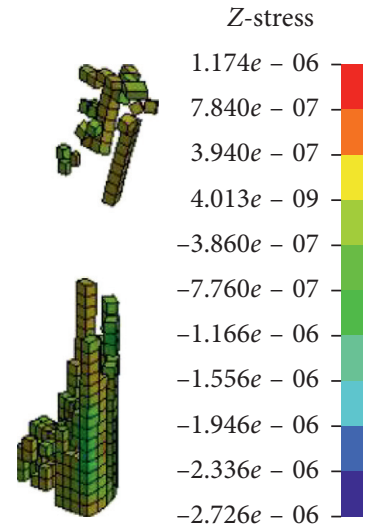

(e)

FIgURE 12: Distribution of the axial stress at a velocity of $10 \mathrm{~m} / \mathrm{s}$. (a) $3 \mu \mathrm{s}$. (b) $13 \mu \mathrm{s}$. (c) $18 \mu \mathrm{s}$. (d) $29 \mu \mathrm{s}$. (e) $1000 \mu \mathrm{s}$.

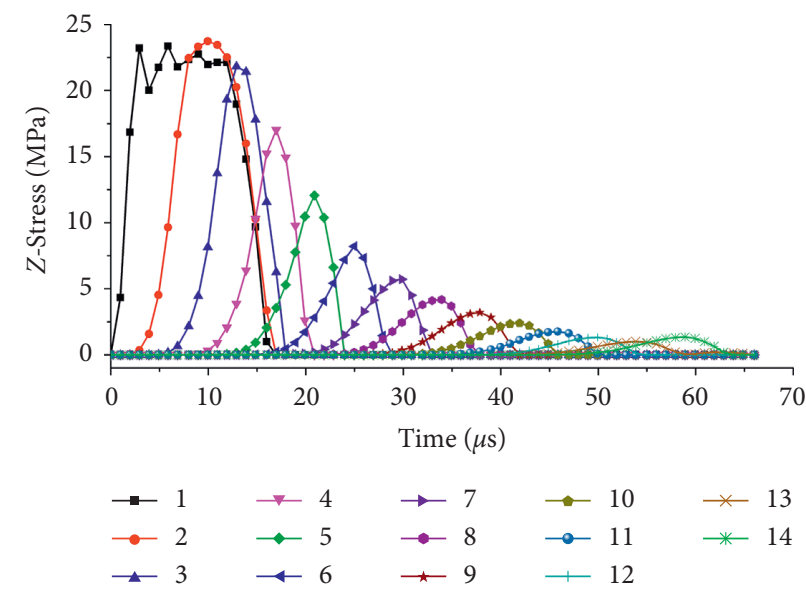

FIgURE 13: Axial stress time history on the central axis. 


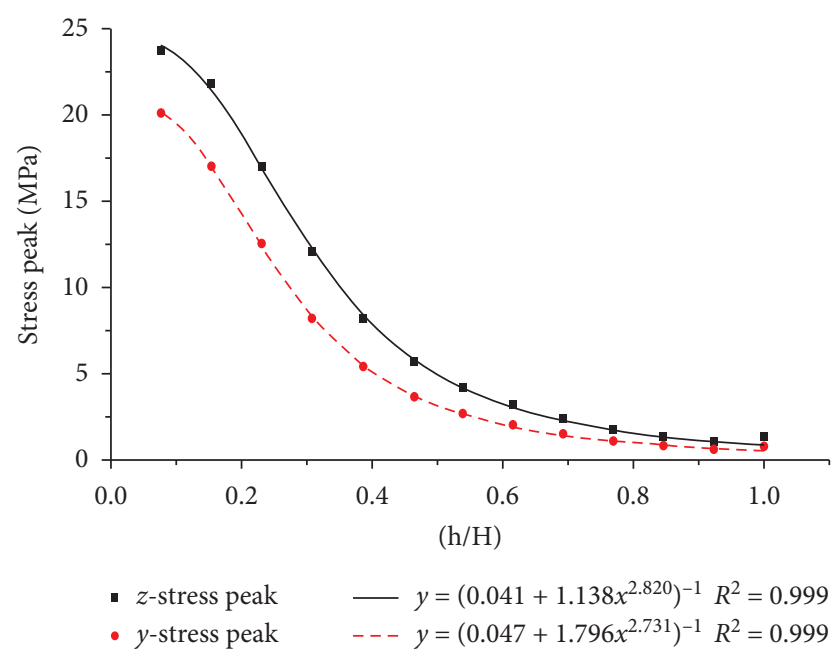

FIgURE 14: Distribution of the axial and radial stress peaks.

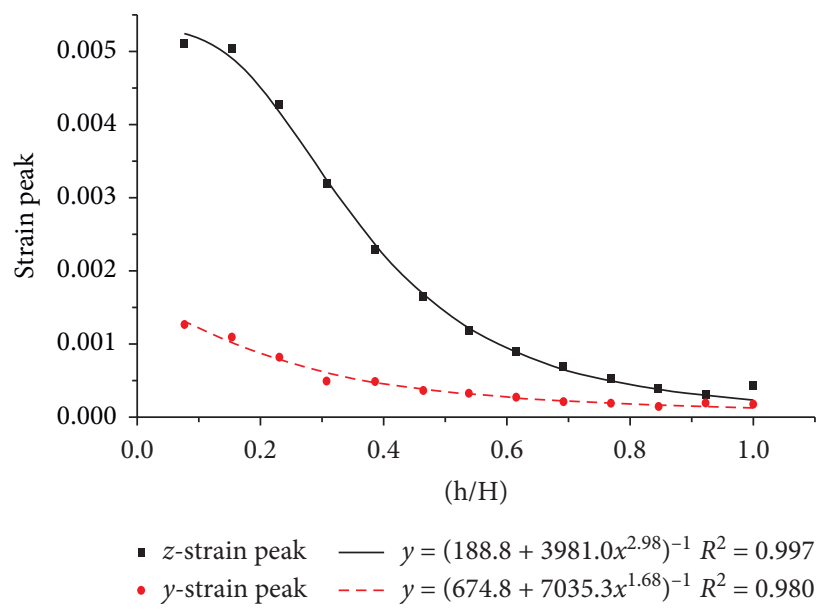

Figure 15: Distribution of the axial and radial strain peaks.

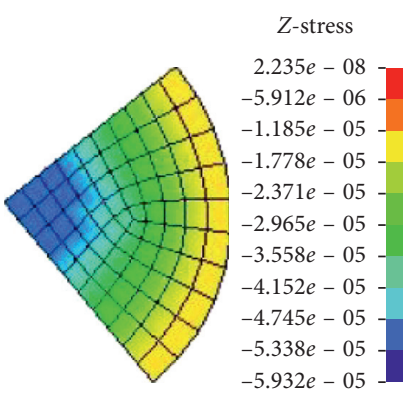

(a)

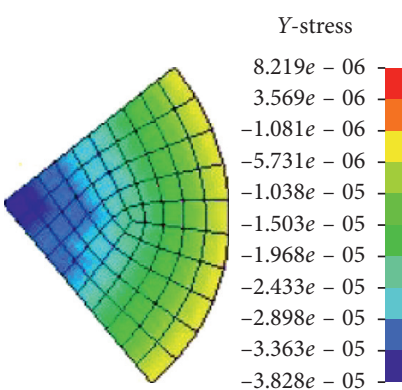

(b)

Figure 16: Distribution of the stress on the cross section at a velocity of $10 \mathrm{~m} / \mathrm{s}$ : (a) axial stress and (b) radial stress.

increases almost simultaneously, and the axial stress peak from the center to the edge on the radial line is continuously reduced.

The distribution of the axial stress peak, radial stress peak, axial strain peak, and radial strain peak at ten element points on the radial line of the contact surface of the cylindrical coal-rock sample is shown in Figures 18 and 19, respectively. The distribution of the axial stress peak, radial stress peak, and axial strain peak at the radial line conforms to the Farazdagiharris-type power function, and the correlation coefficient square $\left(R^{2}\right)$ is greater than 0.94 . The axial stress peak at the same position is greater than the radial 


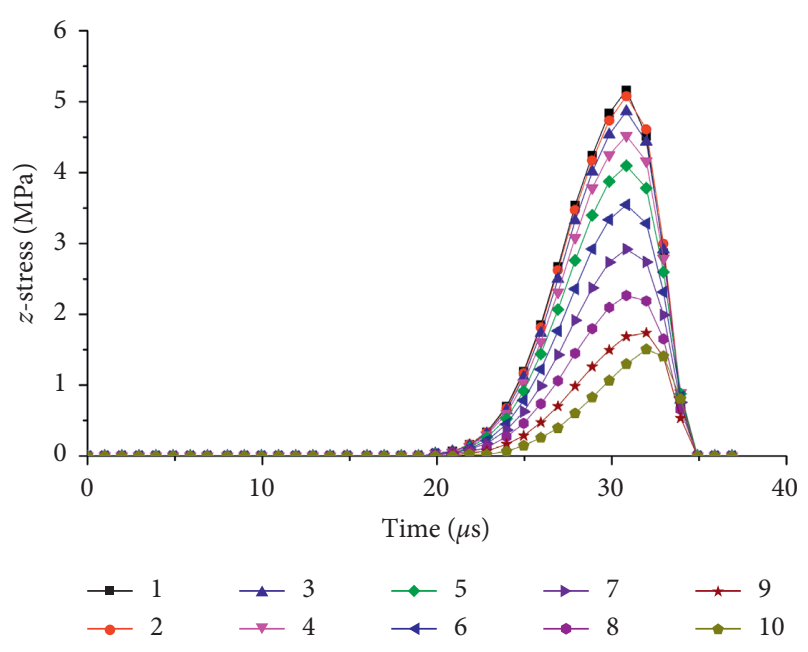

Figure 17: Axial stress time history on the radial line.

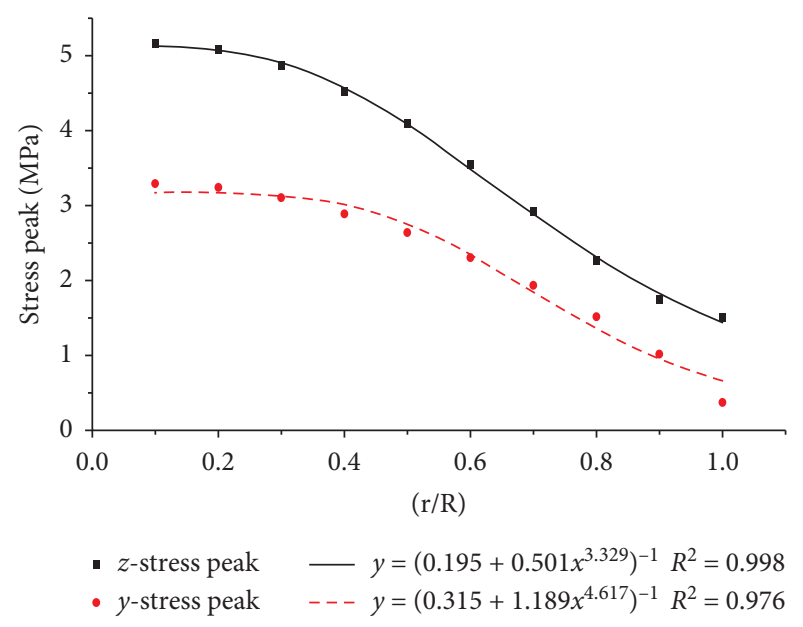

FIgURE 18: Distribution of the axial and radial stress peaks.

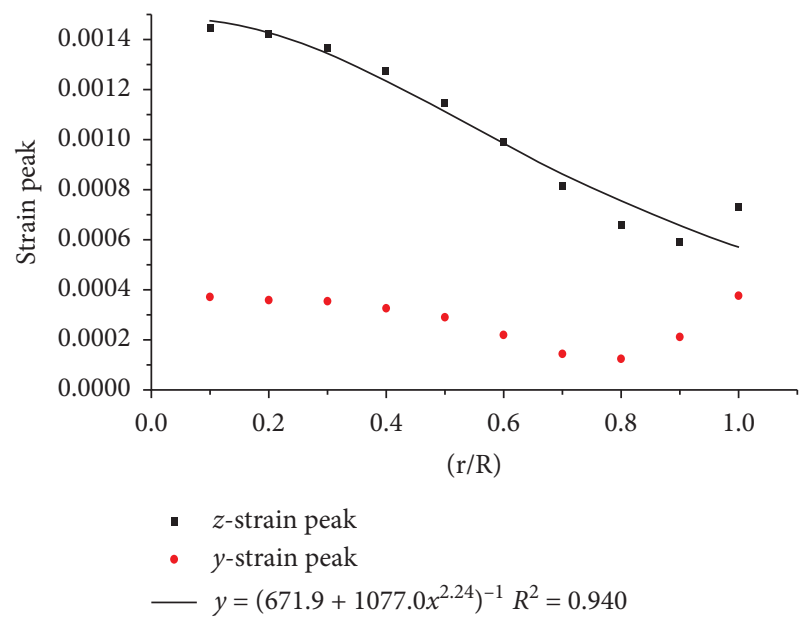

Figure 19: Distribution of the axial and radial strain peaks.

stress peak, and the axial strain peak is greater than the radial strain peak. The strain near the edge on the radial line increases due to the unconstrained edge and greater deformation under the same force.
For plastic deformation of coal and rock masses under stress, the impact stress wave is transmitted and reflected at the interface of the elastic and plastic coal bodies. The wave impedance of the plastic coal is smaller than the wave impedance of the elastic coal, and the wave velocity of the coal mass particle is expressed as

$$
v=\frac{-\sigma}{\rho c}
$$

where $\sigma, \rho c, \rho c_{l}$, and $\rho c_{e}$ are defined as the stress, wave impedance, wave impedance of the plastic coal, and wave impedance of the elastic coal, respectively.

Because $\rho v c_{l}<\rho v c_{e}$, the stress in the plastic zone of the coal and rock mass is less than that in the unchanging elastic zone in the front; in other words, the stress behind the direction of propagation of the stress wave is smaller than that of the front. In the propagation direction of the compressive stress, the stress at the front of the elastic-plastic contact is greater than the stress at the rear. Relatively, tensile stress is generated on the elastic-plastic contact. Under the action of tensile stress, the coal and rock masses are prone to damage.

The numerical simulation results show that the axial stress produces tensile stress in the axial propagation direction, which is consistent with the theoretical analysis.

\section{Conclusion}

Under impact loading, the effective stress of the cylindrical coal-rock sample moves from the edge of the contact surface to the center and reaches the maximum stress at this location. Then, the coal-rock samples break at the center, and the damage develops downward along the axial direction.

(1) The critical effective stress and strain have an exponential function relationship with the impact velocity, and the critical time has a linear relationship with the impact velocity.

(2) The kinetic energy of the impact bars at different impact speeds is approximately equal to the total energy obtained by the cylindrical coal-rock samples. The cylindrical coal-rock sample will be destroyed after the internal energy peak reaches a certain value under different impact speeds. The energy change law of the cylindrical coal-rock sample is consistent with the destruction morphology of the cylindrical coal-rock sample.

(3) The axial stress peaks in the severely damaged part have a linear relationship with the impact speed, the axial stress attenuates rapidly after passing the stress yield point, and the axial strain does not increase continuously. This is consistent with the conclusion of the SHPB dynamic experiment.

(4) The peak distributions of the axial stress, axial strain, radial stress, and radial strain on the central axis and radial line are in accordance with the Farazdagiharris-type power function. The axial stress 
produces tensile stress in the axial propagation direction. The axial stress peak and strain peak at the same position are greater than the radial stress peak and strain peak, respectively.

\section{Data Availability}

The primary data used to support the findings of this study are available from the corresponding author upon request.

\section{Conflicts of Interest}

The authors declare that they have no conflicts of interest.

\section{Authors' Contributions}

This paper is the result of collaborative teamwork. Hongqing Zhu conceptualized the study. Hongqing Zhu and Shuhao Fang were responsible for methodology. Shuhao Fang and Yilong Zhang were responsible for software development. Shuhao Fang and Yan Wu performed formal analysis. Shuhao Fang wrote the article.

\section{Acknowledgments}

This study was funded by the National Key R\&D Program of China (Grant no. 2016YFC0801800), the National Natural Science Foundation of China (Grant nos. 51704299 and 51804311), and the Fundamental Research Funds for the Central Universities (2020YJSAQ13).

\section{References}

[1] M. Jaszczuk and A. Pawlikowski, "A model of equilibrium conditions of roof rock mass giving consideration to the yielding capacity of powered supports," Archives of Mining Sciences, vol. 62, no. 4, pp. 689-704, 2017.

[2] P. Konicek and P. Waclawik, "Stress changes and seismicity monitoring of hard coal longwall mining in high rockburst risk areas," Tunnelling and Underground Space Technology, vol. 81, pp. 237-251, 2018.

[3] K. A. Perry and R. A. Meyr, "Explosion testing of a polycarbonate safe haven wall," Archives of Mining Sciences, vol. 61, no. 4, pp. 809-821, 2016.

[4] A. Pytlik, S. Prusek, and W. Masny, "A methodology for laboratory testing of rockbolts used in underground mines under dynamic loading conditions," Journal of the Southern African Institute of Mining and Metallurgy, vol. 116, no. 7, pp. 1101-1110, 2016.

[5] M. Genis, H. Akcin, O. Aydan, and G. Bacak, "Investigation of possible causes of sinkhole incident at the Zonguldak Coal Basin, Turkey," Geomechanics and Engineering, vol. 16, pp. 177-185, 2018.

[6] X. Liu, D. Song, X. He, Z. Wang, M. Zeng, and K. Deng, "Nanopore structure of deep-burial coals explored by AFM," Fuel, vol. 246, pp. 9-17, 2019.

[7] A. T. Iannacchione and S. C. Tadolini, "Occurrence, predication, and control of coal burst events in the U.S," International Journal of Mining Science and Technology, vol. 26, no. 1, pp. 39-46, 2016.
[8] J. He, L. M. Dou, W. Cai, Z. L. Li, and Y. L. Ding, "In situ test study of characteristics of coal mining dynamic load," Shock and Vibration, vol. 2015, Article ID 121053, 2015.

[9] B. H. Kim, G. Walton, M. K. Larson, and S. Berry, "Experimental study on the confinement-dependent characteristics of a Utah coal considering the anisotropy by cleats," International Journal of Rock Mechanics and Mining Sciences, vol. 105, pp. 182-191, 2018.

[10] S. Liu, R. Zhang, Z. Karpyn, H. Yoon, and T. Dewers, "Investigation of accessible pore structure evolution under pressurization and adsorption for coal and shale using smallangle neutron scattering," Energy \& Fuels, vol. 33, no. 2, pp. 837-847, 2019.

[11] K. H. S. M. Sampath, M. S. A. Perera, D. Elsworth et al., "Effect of coal maturity on CO2-based hydraulic fracturing process in coal seam gas reservoirs," Fuel, vol. 236, pp. 179-189, 2019.

[12] J. S. Yoon, A. Zang, and O. Stephansson, "Simulating fracture and friction of Aue granite under confined asymmetric compressive test using clumped particle model," International Journal of Rock Mechanics and Mining Sciences, vol. 49, pp. 68-83, 2012.

[13] J. B. Zhu, T. Zhou, Z. Y. Liao, L. Sun, X. B. Li, and R. Chen, "Replication of internal defects and investigation of mechanical and fracture behaviour of rock using $3 \mathrm{D}$ printing and 3D numerical methods in combination with X-ray computerized tomography," International Journal of Rock Mechanics and Mining Sciences, vol. 106, pp. 198-212, 2018.

[14] T. Zhou, J. B. Zhu, Y. Ju, and H. P. Xie, "Volumetric fracturing behavior of $3 \mathrm{D}$ printed artificial rocks containing single and double 3D internal flaws under static uniaxial compression," Engineering Fracture Mechanics, vol. 205, pp. 190-204, 2019.

[15] S. Mishra, T. Chakraborty, V. Matsagar, J. Loukus, and B. Bekkala, "High strain-rate characterization of deccan trap rocks using SHPB device," Journal of Materials in Civil Engineering, vol. 30, Article ID 04018059, 2018.

[16] S. Mishra, A. Khetwal, and T. Chakraborty, "Dynamic characterisation of gneiss," Rock Mechanics and Rock Engineering, vol. 52, no. 1, pp. 61-81, 2019.

[17] X. Liu, F. Dai, R. Zhang, and J. Liu, "Static and dynamic uniaxial compression tests on coal rock considering the bedding directivity," Environmental Earth Sciences, vol. 73, no. 10, pp. 5933-5949, 2015.

[18] J. Feng, E. Wang, R. Shen, L. Chen, X. Li, and Z. Xu, "Investigation on energy dissipation and its mechanism of coal under dynamic loads," Geomechanics and Engineering, vol. 11, no. 5, pp. 657-670, 2016.

[19] T.-B. Yin, P. Wang, X.-B. Li, R.-H. Shu, and Z.-Y. Ye, "Effects of thermal treatment on physical and mechanical characteristics of coal rock," Journal of Central South University, vol. 23, no. 9, pp. 2336-2345, 2016.

[20] W. Wang, H. Wang, D. Li, H. Li, and Z. Liu, "Strength and failure characteristics of natural and water-saturated coal specimens under static and dynamic loads," Shock and Vibration, vol. 2018, pp. 1-15, 2018.

[21] F. Gong, H. Ye, and Y. Luo, "The effect of high loading rate on the behaviour and mechanical properties of coal-rock combined body," Shock and Vibration, vol. 2018, pp. 1-9, 2018.

[22] W. Wang, S. Zhang, H. Li, S. Gong, and Z. Liu, "Analysis of the dynamic impact mechanical characteristics of prestressed saturated fractured coal and rock," Advances in Civil Engineering, vol. 2019, pp. 1-10, 2019.

[23] Z. Yang, C. Fan, T. Lan et al., "Dynamic mechanical and microstructural properties of outburst-prone coal based on compressive SHPB tests," Energies, vol. 12, no. 22, p. 4236, 2019. 
[24] Z. Yin, W. Chen, H. Hao et al., "Dynamic compressive test of gas-containing coal using a modified split Hopkinson pressure bar system," Rock Mechanics and Rock Engineering, vol. 53, no. 2, pp. 815-829, 2019.

[25] X. Kong, E. Wang, S. Li, H. Lin, Z. Zhang, and Y. Ju, "Dynamic mechanical characteristics and fracture mechanism of gasbearing coal based on SHPB experiments," Theoretical and Applied Fracture Mechanics, vol. 105, p. 102395, 2020.

[26] D. Ai, Y. Zhao, Q. Wang, and C. Li, "Crack propagation and dynamic properties of coal under SHPB impact loading: experimental investigation and numerical simulation," Theoretical and Applied Fracture Mechanics, vol. 105, p. 102393 , 2020.

[27] Z. Y. Liao, J. B. Zhu, K. W. Xia, and C. A. Tang, "Determination of dynamic compressive and tensile behavior of rocks from numerical tests of split Hopkinson pressure and tension bars," Rock Mechanics and Rock Engineering, vol. 49, no. 10, pp. 3917-3934, 2016.

[28] D.-X. Li, W. Liu, C.-Z. Fan, and S. Fang, "Dynamic characteristics of satellite solar arrays under the deployment shock in orbit," Shock and Vibration, vol. 2018, pp. 1-8, 2018.

[29] E. Kapusuz, B. Yılmaz, and İ. Gökalp, "Assessment of global and network models of devolatilization for numerical analysis of pulverized coal combustion," Combustion Science and Technology, vol. 191, no. 3, pp. 520-537, 2018.

[30] Y. Hao, H. Hao, and X. H. Zhang, "Numerical analysis of concrete material properties at high strain rate under direct tension," International Journal of Impact Engineering, vol. 39, no. 1, pp. 51-62, 2012.

[31] Q. M. Li, Y. B. Lu, and H. Meng, "Further investigation on the dynamic compressive strength enhancement of concrete-like materials based on split Hopkinson pressure bar tests. Part II: numerical simulations," International Journal of Impact Engineering, vol. 36, no. 12, pp. 1335-1345, 2009.

[32] X. Li, Y. Zou, and Z. Zhou, "Numerical simulation of the rock SHPB test with a special shape striker based on the discrete element method," Rock Mechanics and Rock Engineering, vol. 47, no. 5, pp. 1693-1709, 2013.

[33] J. B. Zhu, Z. Y. Liao, and C. A. Tang, "Numerical SHPB tests of rocks under combined static and dynamic loading conditions with application to dynamic behavior of rocks under in situ stresses," Rock Mechanics and Rock Engineering, vol. 49, no. 10, pp. 3935-3946, 2016.

[34] W. C. Zhu, Y. Bai, X. B. Li, and L. L. Niu, "Numerical simulation on rock failure under combined static and dynamic loading during SHPB tests," International Journal of Impact Engineering, vol. 49, pp. 142-157, 2012.

[35] J.-J. Zhao, Y. Zhang, and P. G. Ranjith, "Numerical simulation of blasting-induced fracture expansion in coal masses," International Journal of Rock Mechanics and Mining Sciences, vol. 100, pp. 28-39, 2017.

[36] L. Majidi, N. Usefi, and R. Abbasnia, "Numerical study of RC beams under various loading rates with LS-DYNA," Journal of Central South University, vol. 25, no. 5, pp. 1226-1239, 2018.

[37] X. Zhai, S. Wu, H. Li, K. Wang, W. Wang, and X. Song, "Experimental and numerical investigation on dynamic behaviors of the concrete wall in underground coal mine with hydraulic blasting demolition," Journal of Vibroengineering, vol. 19, no. 3, pp. 2043-2062, 2017.

[38] P. Yuan, Q. Y. Ma, and D. D. Ma, "Stress uniformity analyses on nonparallel end-surface rock specimen during loading process in SHPB tests," Advances in Civil Engineering, vol. 2018, p. 5406931, 2018.
[39] B. J. Xie, Z. M. Zhao, X. M. Xu, and Y. Zhao, "HJC constitutive model and numerical simulation of hammer damagewith gascontaining coal," Journal of China Coal Society, vol. 43, pp. 2789-2799, 2018.

[40] T. J. Holmquist, G. R. Johnson, and W. H. Cook, "A computational constitutive model for concrete subjected to large strains, high strain rates, and high pressures," in Proceedings of the 14th International Symposium on Ballistics, pp. 591-600, Qucbec, Canada, September, 1993.

[41] X. Kong, Q. Fang, H. Wu, and Y. Peng, "Numerical predictions of cratering and scabbing in concrete slabs subjected to projectile impact using a modified version of HJC material model," International Journal of Impact Engineering, vol. 95, pp. 61-71, 2016.

[42] P. Jonsson, P. Jonsén, P. Andreasson, T. Lundström, and J. Hellström, "Smoothed particle hydrodynamic modelling of hydraulic jumps: bulk parameters and free surface fluctuations," Engineering, vol. 8, no. 6, pp. 386-402, 2016.

[43] X. H. Long, A. Turgun, R. Yue, Y. T. Ma, and H. Luo, "Influence factors analysis of RC beams under falling weight impact based on HJC model," Shock and Vibration, vol. 2018, Article ID 4731863, 2018.

[44] T. H. Lv, X. W. Chen, and G. Chen, "The 3D meso-scale model and numerical tests of split Hopkinson pressure bar of concrete specimen," Construction and Building Materials, vol. 160, pp. 744-764, 2018.

[45] C. Fan, S. Li, D. Elsworth, J. Han, and Z. Yang, "Experimental investigation on dynamic strength and energy dissipation characteristics of gas outburst-prone coal," Energy Science \& Engineering, vol. 8, no. 4, pp. 1015-1028, 2020.

[46] Y. Wang, Y. Yang, Y. Zhang, and J. Wang, "Dynamic mechanical properties of coals subject to the low temperature-impact load coupling effect," Sci Rep, vol. 9, p. 20218, 2019. 